\title{
COMPARATIVE STUDY BETWEEN INFRARED THERMOGRAPHY AND LASER DOPPLER VIBROMETRY APPLIED TO FLAWS INDENTIFICATION IN COMPOSITE MATERIALS
}

\author{
${ }^{1}$ Daniel Pedro Willemann, ${ }^{2}$ Sinthya Gonçalves Tavares, ${ }^{1}$ Paolo Castellini, ${ }^{2}$ Roberto Márcio de Andrade \\ ${ }^{1}$ Dipartimento di Meccanica - Università Politecnica delle Marche, Ancona, Italy, Phone: +39-071-2204508, \\ Fax: +39-071-2204801, e-mail: a.agnani@mm.univpm.it \\ ${ }^{2}$ Departamento de Engenharia Mecânica da Universidade Federal de Minas Gerais, \\ Belo Horizonte, MG - Brazil, Phone: +55-31-3499-5140, \\ Fax: +55-31-3499-5140, gtavar@terra.com.br
}

Keywords: NDT techniques, Thermography, laser Doppler vibrometry, composite materials, mathematical model

\section{ORAL PRESENTATION}

There are many NDT techniques available but only a few allow in situ analysis. Thus, the requirements for non-destructive evaluation are continuing to be driven by the need for lower cost methods and instruments with greater reliability, sensitivity, user friendliness and high operational speed as well as applicability to increasingly complex materials and structures [1]. Both infrared termography and laser Doppler Vibrometer accomplish these characteristics and, for this reason, are widely employed in the NDT sector.

In this work, a comparative study between laser Doppler vibrometry and infrared thermography applied to the damage detection in composite material is presented. A mathematical model was implemented in order to validate the results obtained experimentally through the thermographic technique. The thermal measurements uncertainty and the noise of the LDV system, which are limitations of each methodology, are also discussed.

The experimental procedure was carried out in the Mechanical and Thermal Measurements laboratory of the Mechanical Engineering Department of the Università Politecnica delle Marche. The honeycomb panel used in this work has its four layered top part made with a combination of glass-fibre fabric type RE 200 and E277 epoxy resin. Three wax inclusions were inserted in certain positions among the layers during its manufacturing process in order to create the flaws. After, by warming, the wax inclusions were eliminated from the panel to simulate real delaminations. Figure 1 shows the geometry and the position of the $20 \mathrm{~mm}$ circular defects in the upper part of the honeycomb panel.

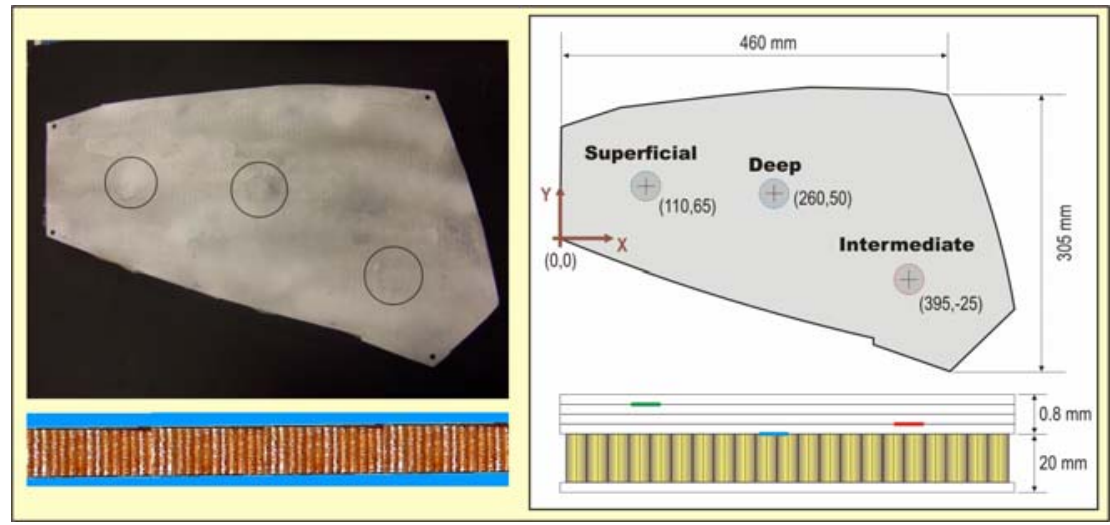

Figure 1 - Honeycomb Panel

In the mathematical model employed for the numerical validation of the thermographic investigations, the Fourier equation has been used, considering a transient regimen, without heat generation, in three-dimensional cartesian coordinates. During the investigations, the lateral sides of the sample have been isolated which allowed to consider the heat flow as one-dimensional. For the Fourier equation solution, numerical technique with formularization in finite volumes has been employed. A program, written in FORTRAN ${ }^{\circledR}$, has been developed for the solution evaluation. The number of control volumes has been defined from mesh test and criterion of convergence based on the comparison between the numerical and analytical solutions for the temperature reached at each point (only differences smaller than $10^{-5}$ had been accepted). In the analytical solution, the panel has been considered as a semi-infinite solid.

Both pulsed and modulated Thermography were employed and the testing procedure suggested in [3] has been followed. Regarding the uncertainty analysis, the methodology indicated in [4] and [5] has been used and more details will be given in the final paper.

The Figure 2 shows, for the maximum contrast, two temperature maps: (A) obtained by the infrared camera and (B) obtained by means of MATLAB program. Both maps use pulsed thermography.

Images analysis allowed the identification of the flaws since the temperature difference between the unflawed and flawed areas was twice greater than $0.8^{\circ} \mathrm{C}$ that is the maximum uncertainty for the measurement set. The two deepest flaws are better defined by means of modulated Thermography.In the final work, further maps obtained by means numerical solutions using FORTRAN ${ }^{\circledR}$ program and modulated Thermography will be shown.

The analysis of the numerical results for the more superficial fail indicate the validation of the experimental datas because the temperature difference between the fail and their neighborhood is lesser than the uncertainty of measurement. Figure 3 shows the experimental and numerical surface temperature decay for the area with and whitout flaw. 

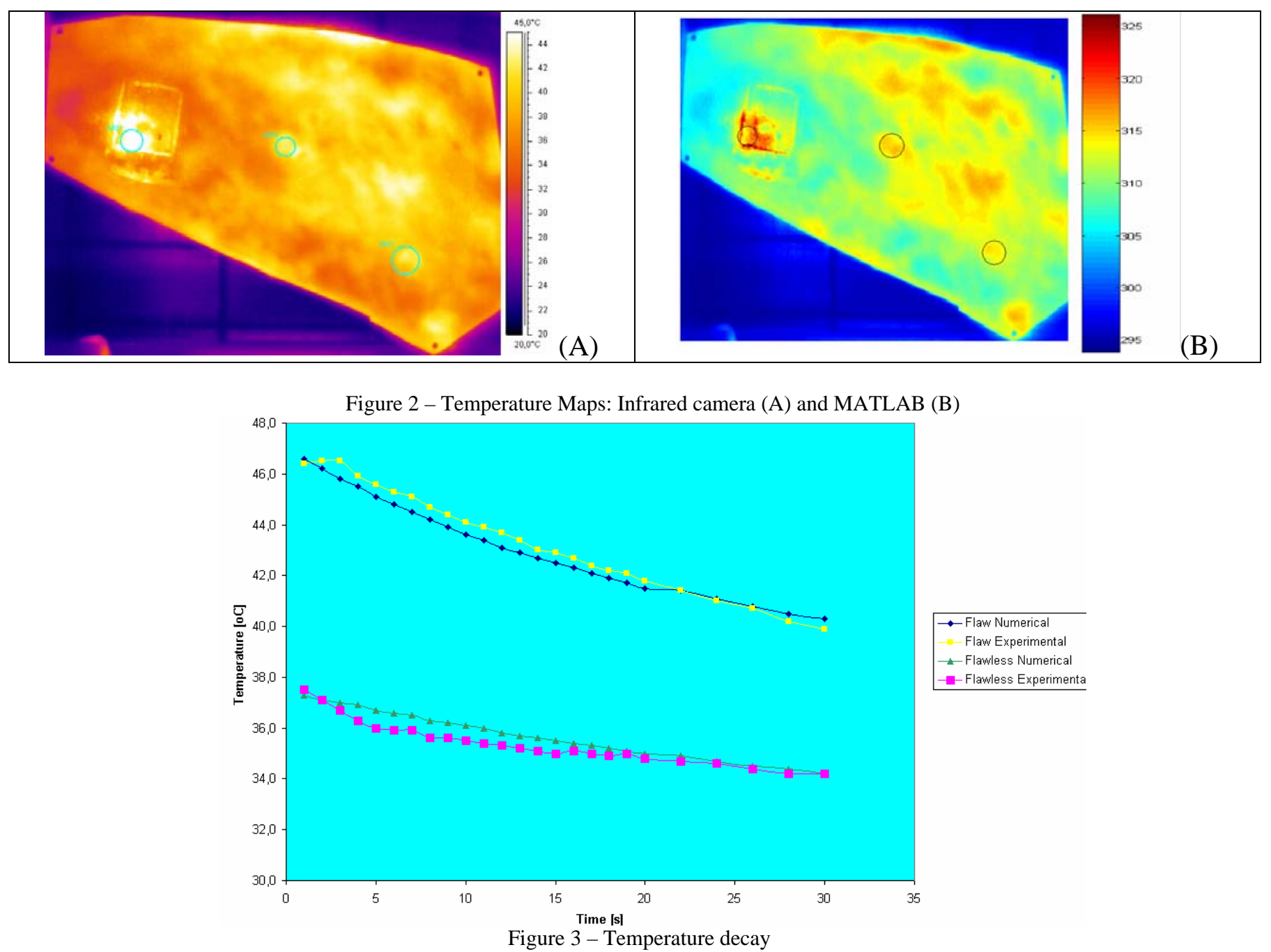

The dashed circles in Figure 4 show different maps highlighting the delaminations present in the panel: (A) in a RMS velocity map at $11.15 \mathrm{kHz}$ and (B) in a PCA (Principal Component Analysis) map. Both maps were obtained from a measurement performed by a scanning laser Doppler vibrometer. In this case, a speaker driven by white noise signal has been used as excitation device and $20 \mathrm{kHz}$ of measurement bandwidth and 1600 spectral lines were employed during the measurements. A detailed discussion of the results will be done in the final paper.
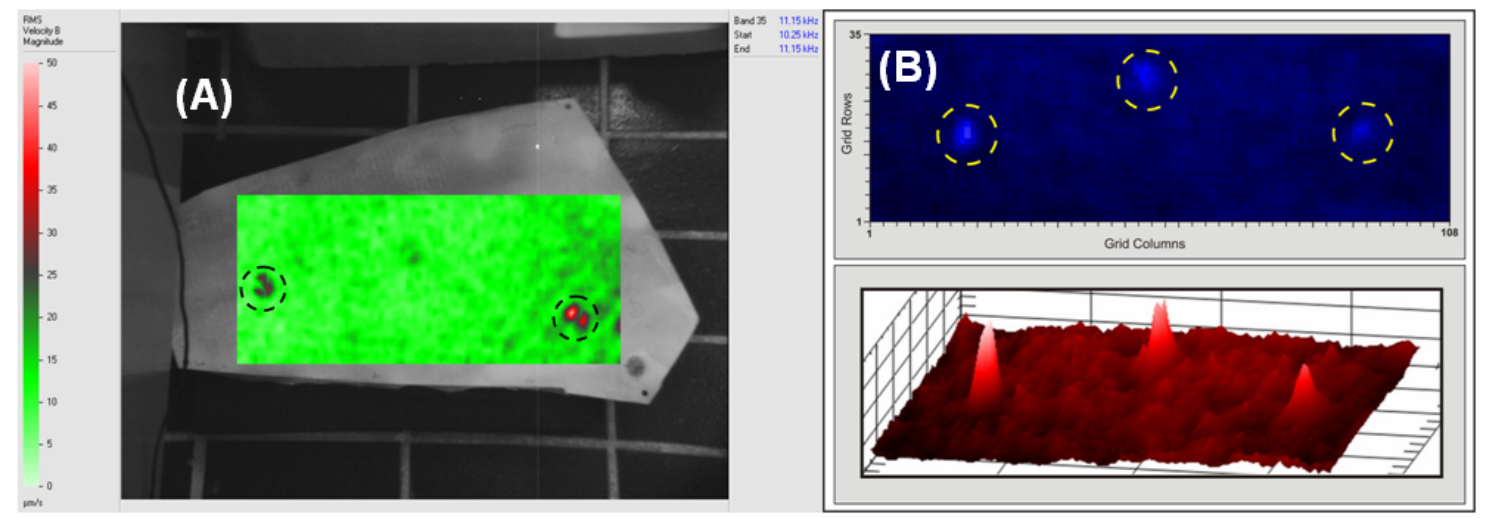

Figure 4 - Laser Doppler Vibrometry Measurements: RMS Map (A) and PCA Map (B)

\section{References}

(1) Meola, C., Calomagno, G. M., Giorleo, L., “The use of infrared thermography for materials characterization”, Journal of Materials Processing Technology, Vol. 155-156, pp.1132-1137, 2004.

(2) Tavares. S. G., Andrade, R. M., “Metodologia de ensaio e análise de incerteza na aplicação da termografia”, 2003, Anais do III Congresso Brasileiro de Metrologia, Recife, PB, Brasil.

(3) Tavares, S. G., Cunha, A. M., Andrade, R. M., "Metodologia Experimental para Aplicação da Termografia em Ensaios Térmicos não Destrutivos”, 2004, Proceedings of the $10^{\text {th }}$ Congress of Thermal Sciences and Engineering - ENCIT 2004, Brazilian Society of Mechanical Sciences and Engineering, ABCM, Rio de Janeiro, Brazil.

(4) Chrzanowski, K., Fischer, J., Matyszkiel, R., "Testing and evaluation of thermal cameras for absolute temperature measurement”, 2000, Journal of Optical Engineering vol. 39, no 9, pp. 2535-2544. 